\begin{tabular}{|c|c|c|c|c|c|c|}
\hline \multirow{4}{*}{ Impact Factor: } & ISRA (India) & $=3.117$ & SIS (USA) & $=0.912$ & ICV (Poland) & $=6.630$ \\
\hline & ISI (Dubai, UAE & $=0.829$ & РИНЦ (Russia & $=0.156$ & PIF (India) & $=1.940$ \\
\hline & GIF (Australia) & $=0.564$ & ESJI (KZ) & $=8.716$ & IBI (India) & $=4.260$ \\
\hline & JIF & $=1.500$ & SJIF (Morocce & $=5.667$ & OAJI (USA) & $=0.350$ \\
\hline
\end{tabular}

\begin{tabular}{|c|c|}
\hline $\begin{array}{l}\text { SOI: } \frac{1.1 / \mathrm{TA}}{\text { International Sc }} \\
\text { Theoretical \& A }\end{array}$ & $\begin{array}{l}\text { IS DOI: } 10.15863 / \mathrm{TAS} \\
\text { cientific Journal } \\
\text { aplied Science }\end{array}$ \\
\hline p-ISSN: 2308-4944 (print) & e-ISSN: 2409-0085 (online) \\
\hline Year: $2019 \quad$ Issue: 06 & Volume: 74 \\
\hline Published: 30.06 .2019 & http://T-Science.org \\
\hline
\end{tabular}

SECTION 31. Jurisprudence.
QR - Issue
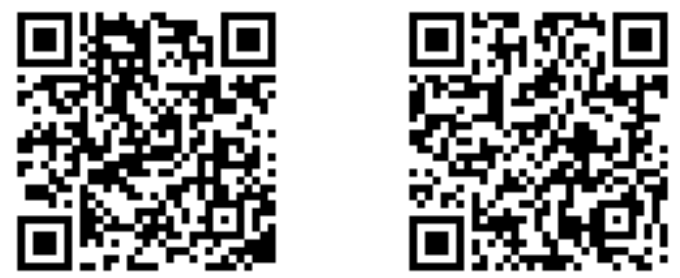

Irina Leonidovna Vishnevskaya

IP.Pravovaya information and services

Subject image of forensic examination, Russia,

\title{
THE STRUCTURE OF THE UNIVERSAL ACTIVITIES IN THE FORENSIC EXAMINATION
}

Abstract: The article deals with the main aspects that determine the system relationships that form the structure of all-General activities in forensic examination; reveals the mechanism of preservation of the basic properties of activity, manifested in the dynamics of differences that form the difference of features, the totality of which ensures the integrity of the result, based on scientific methodology.

Key words: the action structure of activities, the categories of structure, structural system analysis in sedoprothe production of legal laws judicial-expert activity, concept, process sedopro the production.

Language: Russian

Citation: Vishnevskaya, I. L. (2019). The structure of the universal activities in the forensic examination. ISJ Theoretical \& Applied Science, 06 (74), 586-590.

Soi: http://s-o-i.org/1.1/TAS-06-74-72 Doi: roskef https://dx.doi.org/10.15863/TAS.2019.06.74.72

\section{СТРУКТУРА ВСЕОБЩЕЙ ДЕЯТЕЛЬНОСТИ В СУДЕБНОЙ ЭКСПЕРТИЗЕ}

Аннотация: В статье рассмотрены основные аспекты, определяющие системные связи, образующие структуру всеобщей деятельности в судебной экспертизе; раскрывается механизм сохранения основных свойств деятельности, проявляюшийся в динамике различий, формирующих разничу признаков, совокупность которых, обеспечивает целостность полученного результата, основанного на научной методологии.

Ключевые слова: действие, структура деятельности, категории структуры, структурно-системный анализ в судопроизводстве, правовые закономерности судебно-экспертной деятельности, концепиия, проиесс в судопроизводстве.

\section{Introduction}

\section{Рассматривая}

определяются

судопроизводства, является судебная экспертиза.

Диалектический метод, являющийся основой судебной экспертной деятельности, определяет категорию структуры, обеспечивающую динамику познания.

В результате, деятельность судебной экспертизы, как процессуального действия, образует систему закономерностей правового и научного характера, определяя упорядоченность и динамику неоспоримости полученных доказательств. Если относиться к деятельности судебной экспертизы как научно-практической с определенным целостным результатом, то формируются её структуры организационного, правового и методологического характера.

\section{Materials and Methods}

Судебная экспертиза, состоящая из различных видов и форм исследования, определяет систему взаимодействий субъекта, объекта, права, объединяет ее задачи в процессе доказывания. Поэтому в экспертной деятельности важнейшая роль отводится индивидуальным и интеллектуальным качествам эксперта, поскольку, познание осуществимо субъектом, имеющим личностный характер [1, с. 57].

Коммуникативная деятельность возникает во взаимодействии с участниками процесса как и конструктивная, связанная с планированием процесса производства судебной экспертизы [2, c.63]. 


\begin{tabular}{llllll} 
& ISRA (India) $=\mathbf{3 . 1 1 7}$ & SIS (USA) & $=\mathbf{0 . 9 1 2}$ & ICV (Poland) & $=\mathbf{6 . 6 3 0}$ \\
Impact Factor: & ISI (Dubai, UAE) $=\mathbf{0 . 8 2 9}$ & PUHL (Russia) $=\mathbf{0 . 1 5 6}$ & PIF (India) & $=\mathbf{1 . 9 4 0}$ \\
& GIF (Australia) $=\mathbf{0 . 5 6 4}$ & ESJI (KZ) & $=\mathbf{8 . 7 1 6}$ & IBI (India) & $=\mathbf{4 . 2 6 0}$ \\
& JIF & $\mathbf{1 . 5 0 0}$ & SJIF (Morocco) $=\mathbf{5 . 6 6 7}$ & OAJI (USA) & $\mathbf{0 . 3 5 0}$ \\
\hline
\end{tabular}

Организаторская деятельность судебного эксперта связывается с конструктивной, так как учитывает планирование предстоящей работы относительно основного процесса судопроизводства. Это позволяет судебному эксперту реализовать практически планы и решения в проведении профессиональной деятельности относительно её всеобщей структуры. Базисной характеристикой деятельности судебной экспертизы является систематичность, способствующая накоплению опыта практической работы, методик и расчетов. При этом создается возможность прогнозирования заданных действий, причин и следствий. Возникает банк профессиональных умений, исходя из анализа накопленных данных из судебной практики. Профессиональная деятельность судебного эксперта имеет характеристики учебной деятельности, состоящей из действий ориентировочного, исполнительного и контрольного содержания, которые через логической операции определяют мысленный переход от частного к общему заданной модели абстрактного содержания. В итоге система действий, объединенная единым доказательным мотивом обеспечивает достижение цели деятельности судебной экспертизы [3, с.115].

Для всякой деятельности и судебная экспертиза не исключение, посредством логических операций с определенной мотивацией, происходит изменение самого субъекта, в части его умственной и пространственной организации. Из чего следует, что деятельность судебной экспертизы проходит путь интериоризации, то есть, взаимодействия и превращения из внешнего мира реальной деятельности во внутренний мир умственной деятельности. То есть, из определённых операционных действий, объединенных одной мотивацией и целью, происходит преобразование из множества объективных предметов и причин, в единое развитие мировоззрения отдельного субъекта [4, c. 48$]$.

Таким образом, установлена единая психологическая составляющая всеобщей структуры деятельности судебной экспертизы, поскольку, включает действия по принятию решения, его реализации и контролю [8, с.79].

Рассматривая множество понятий и отношений анализируемого процесса можно определить единство и неоспоримость доказательств в судебной экспертизе, которое формирует действие, как структуру начальной ориентировочной части деятельности. Это приводит к быстрому принятию решения, которое обеспечивает правильное исполнение действий, рациональный выбор единственного решения, являющегося одним из множества возможных [5, c.247].

Базисность социального познания, составляющего основу всеобщей деятельности судебной экспертизы как научного обобщения, описывает и объясняет факты, которые прогнозируют новые отношения, анализирующих процессы по дифференцированным признакам.

Из этого следует, что наиболее определяющая роль в деятельности судебной экспертизы, как творческого процесса, отводится индивидуальным качествам эксперта с одновременным присутствием закономерностей, последовательностей выстроенной всеобщей структуры деятельности судебной экспертизы [6, c.94].

Судебное заключение основанное на гносеологическом познании субъектом объекта, последовательность действий применения научно-обоснованных методов, в соответствии со статьями 4,5 №73-Ф3 от 31.03.2001 г., является документом, с выраженной системой множеств, исследуемых отношений, следствием которых, является доказательство единого целого, метод дедукции, как одного из средств логических доказательств. В результате, концепция всеобщей деятельности судебной экспертизы, как и ее структура, обозначается определённой системой взаимодействий тождеств или противоположностей [8, с.57].

Руководствуясь выстроенной методологией, упорядоченной динамикой производства судебных экспертиз, выявляются важные составляющие факторы творческого исследования.

Следовательно, объект, вошедший в установленный круг ориентировочной основы действия подвергается аналитическому исследованию [10, с.126].

Таким образом, прикладная основа деятельности судебной экспертизы обуславливает синтез научных и практических знаний, обуславливая динамику исследовательской работы, на уровне внутренних, умственных действий.

Возникающая система отношений определяет, что накопленные профессиональные знания эксперта, формируют адекватную систему умственных действий, характеризуя еe, как единый процесс.

Характеризуя деятельность судебной экспертизы, как адекватную систему действий, при которой происходит накопление необходимых знаний с увеличением их диапазона, в связи с обширной судебной практикой, то формируется система познавательных действий заданной логики. Это определяет характер 


\begin{tabular}{llllll} 
& ISRA (India) $=\mathbf{3 . 1 1 7}$ & SIS (USA) & $=\mathbf{0 . 9 1 2}$ & ICV (Poland) & $=\mathbf{6 . 6 3 0}$ \\
Impact Factor: & ISI (Dubai, UAE) $=\mathbf{0 . 8 2 9}$ & PUHL (Russia) $=\mathbf{0 . 1 5 6}$ & PIF (India) & $=\mathbf{1 . 9 4 0}$ \\
& GIF (Australia) $=\mathbf{0 . 5 6 4}$ & ESJI (KZ) & $=\mathbf{8 . 7 1 6}$ & IBI (India) & $=\mathbf{4 . 2 6 0}$ \\
& JIF & $\mathbf{1 . 5 0 0}$ & SJIF (Morocco) $=\mathbf{5 . 6 6 7}$ & OAJI (USA) & $\mathbf{0 . 3 5 0}$ \\
\hline
\end{tabular}

процесса экспертной деятельности и приводит к расширению аналитических профессиональных возможностей [12, с.27].

Действие определено единицей психологического анализа в планомерном переходе от гипотезы к теории системного строения, где разрозненные, как дискретные частицы, элементы и связи, формируют образование нового единого целого. Следовательно, такая единица, анализа, обогащенная элементами различной психологической природы, становится уже системой, порождая уже следующие теории познания, необходимые в деятельности судебной экспертизы, такие, как дедукция, индукция правового пространства [13, с.58].

Данные базисные понятия, о том, что познание субъектом объекта неразрывно связано, как единство бытия, определяют идеи субъективизма и индивидуализма в социальном познании.

В целом, познание есть творческий процесс, который проводит субъект жизнедеятельности. Это приводит к понятию о том, что познание организуется лишь человеком, который и есть предпосылка всякой социальной активности, всякого философского познания. Уровень субъектно-объектных отношений формируется только человеком, который организует орудийный процесс отношений с социальной средой. Это приводит к образованию личностных отношений с образом мира - мерой ответственности жизненных интересов [5, с.118].

Деятельность судебной экспертизы полностью раскрывается через психологическую теорию деятельности, которая устанавливает все аспекты профессионального образа судебного эксперта, выявляющего составляющие деятельности судебной экспертизы, устанавливающего сложные закономерности информации через её обработку и перекодировку отношений исследуемых процессов.

Таким образом, прикладной характер деятельности судебной экспертизы, определяет основные виды судебно-экспертной деятельности - познавательную, конструктивную, коммуникативную, воспитательную и организаторскую.

Познавательная деятельность, как гносеологическая составляющая деятельности, направлена на получение достоверных знаний, адекватно отражающих познавательный объект, и основана на применении специальных знаний, используемых при отборе и выявлении информационных сигналов, фактов, содержащихся в объектах исследования [9, с.73].
Основываясь на приобретенном профессиональном опыте эксперт, выступая субъектом деятельности, становится автором ориентировочной основы действия, на которую в процессе деятельности накладываются знания, факты, входящие в круг уже определённой основы.

Для достижения цели и получения необходимых выводов в процессе доказывания, то есть, успеха деятельности, важно формирование степени обобщения набранных ориентиров, профессиональных знаний, методик классических расчетов.

В судебной экспертизе важная роль отводится процессуальным действиям, как правовой основы структуры всеобщей деятельности судебной экспертизы. Только при соблюдении процесса судопроизводства, представленного в статьях процессуальных кодексов, возможно принятие или не принятие сформированных доказательств, то есть, оценка судом или следствием достигнутых результатов судебного эксперта. Формулируя факторы и составляющие основных аспектов деятельности судебной экспертизы, важное место в экспертном исследовании отведено фактам, относящимся к делу, в том или ином судопроизводстве. Факт это особое предложение, несущее определенное эмпирическое знание, но в зависимости от выбранной позиции теоретических знаний может изменяться. Следовательно, факт в деятельности судебной экспертизы расценивается в качестве исходного, обуславливающего выбор дальнейших исследований. Следовательно, как метод визуализации в деятельности судебной экспертизы может быть принят, как перцептивное действие, как считывание информации объектов, моделей без их изменений, но являющихся основой дальнейших действий,

Процесс подбора методов исследования, для достижения конечного результата - это формирование выводов произведенного исследования. Исследуемое перцептивное действие, которое является единицей деятельности с определённой структурой, состоит из определенных частей - ориентировочной части, исполнительной, корректировочной и контрольной [13, с.49].

Следуя назначению предмета деятельности судебной экспертизы, непосредственно связанной с психологическими аспектами, существенное значение наряду с логическими операциями имеют интеллектуально - идентификационные свойства, такие как запоминание, восприятие, представление. Понятие о восприятии окружающих процессов относящееся к непосредственной деятельности судебной 


\begin{tabular}{llllll} 
& ISRA (India) $=\mathbf{3 . 1 1 7}$ & SIS (USA) $=\mathbf{0 . 9 1 2}$ & ICV (Poland) & $\mathbf{= 6 . 6 3 0}$ \\
Impact Factor: & ISI (Dubai, UAE) $=\mathbf{0 . 8 2 9}$ & PUHЦ (Russia) $=\mathbf{0 . 1 5 6}$ & PIF (India) & $=\mathbf{1 . 9 4 0}$ \\
& GIF (Australia) $=\mathbf{0 . 5 6 4}$ & ESJI (KZ) & $\mathbf{8 . 7 1 6}$ & IBI (India) & $=\mathbf{4 . 2 6 0}$ \\
& JIF & $\mathbf{1 . 5 0 0}$ & SJIF (Morocco) $=\mathbf{5 . 6 6 7}$ & OAJI (USA) & $\mathbf{0 . 3 5 0}$ \\
\hline
\end{tabular}

экспертизы имеет психологическое содержание поскольку участвует в извлечении информации об исследуемом объекте, то есть включает в себя определенные действия, связанные с обследованием. Пользуясь содержанием выбранной ориентировки для конкретного исследования, субъект в непосредственной деятельности для выбора определенных методик, расчетов получает свойства, признаки, необходимые при формировании результатов соответствующей структуры всеобщей деятельности судебной экспертизы [11, с.87].

Общим результатом процесса развития структуры всеобщей деятельности судебной экспертизы являются умственные действия, направленные на формирование общей цели результатов профессиональной деятельности судебного эксперта. Возникающие процессы интериоризации и экстериоризации всеобщей деятельности профессионалов-экспертов отражают механизмы воспитания, развития и совершенствования профессионального мастерства специалистов судебной экспертизы. При этом возникает последовательность действий отражающих системную ориентировку в предмете установленной проблемы.

В процессе всеобщей деятельности судебной экспертизы, как умственного процесса, исходя из судебной практики происходит совмещение этих двух противоположных направлений движения исследовательского процесса в деятельности судебного эксперта.

В активной всеобщей деятельности судебного эксперта психологическая теория деятельности, общий системный анализ и теория планомерного формирования умственных действий принимают прикладной характер с применением социального опыта науки и различных методик теории научного познания и накопленного экспертного мастерства. При этом максимальный профессиональный эффект в организации судебной экспертизы возникает при сбалансированном соотношении процессов науки и практики с построением адекватных умственных действий экспертной судебной деятельности, прошедшей поэтапный путь развития.

В целом, формируется адекватная система деятельности, действий судебного эксперта на основе составления системного типа ориентировки в предмете и организации самой профессиональной деятельности, направленной на построение абсолютной схемы судебной экспертизы целостно-системного характера.

\section{Conclusion}

Исследовательский процесс построения структуры всеобщей деятельности судебной экспертизы включает возможности обобщения различных признаков и свойств объектов относительно их осмысления и придания им характеристик системности. Профессионализм формирования данной деятельности задаётся механизмами организации ориентировочной основы действия, на основе обобщения и систематизации свойств предметов и деятельностей, составляющих основу содержания успешности построения судебной экспертизы. При этом возникает мера самостоятельности относительно разделенности перехода экспертного действия из внешнего плана во внутренний и из разделенного в самостоятельное профессиональное действие судебного эксперта. Это обуславливает творческую основу судебных исследований и индивидуальную ответственность мера которой, установлена статьей УК РФ № 307, и статьями № 73-Ф3 от 31.05.2001 года (с изменениями на 2017 год) «О судебной экспертной деятельности» [7, с.48].

Формирование и исследование структуры обобщённой деятельности судебного эксперта связывается с построением всего профессионального цикла экспертной деятельности, содержание которого выражает единство выполнения всего круга законов процессуального характера, преломлённого через построение высшего уровня целостно-системной экспертной деятельности.

\section{References:}

1. Aver'yanova, T. V. (2017). Kurs obshchej teorii sudeb-noj ekspertizy. (p.407). Moscow: Norma.

2. Arsen'ev, V. D. (1964). Voprosy obshchej teorii su-debnyh dokazatel'stv. (p.179). Moscow: Yurid. Literatura.
3. Belkin, P. C. (1964). Sobiranie, issledovanie $i$ ocenka dokazatel'stv. (p.295). Moscow: Yurid. Literatura.

4. Gal'perin, P. Y. (2000). Vvedenie v psihologiyu. (p.336). Moscow: Universitet. 


\begin{tabular}{llllll} 
& ISRA (India) $=\mathbf{3 . 1 1 7}$ & SIS (USA) $=\mathbf{0 . 9 1 2}$ & ICV (Poland) & $\mathbf{= 6 . 6 3 0}$ \\
Impact Factor: & ISI (Dubai, UAE) $=\mathbf{0 . 8 2 9}$ & PUHЦ (Russia) $=\mathbf{0 . 1 5 6}$ & PIF (India) & $=\mathbf{1 . 9 4 0}$ \\
& GIF (Australia) $=\mathbf{0 . 5 6 4}$ & ESJI (KZ) & $\mathbf{8 . 7 1 6}$ & IBI (India) & $=\mathbf{4 . 2 6 0}$ \\
& JIF & $\mathbf{1 . 5 0 0}$ & SJIF (Morocco) $=\mathbf{5 . 6 6 7}$ & OAJI (USA) & $\mathbf{0 . 3 5 0}$ \\
\hline
\end{tabular}

5. Gegel' (1990). Filosofiya prava. (p.526). Moscow: JT.

6. Dulov, A. B. (1975). Sudebnaya psihologiya. (p.464). Minsk: Vyshejsh. SHkola.

7. (2003). Kommentarij k Federal'nomu zakonu «O gosudarstvennoj sudebno-ekspertnoj deyatel'nosti v Rossijskoj Federacii» ot 31 maya 2001 g. / Pod obshch. red. Kashepova V.P. (Eds.). (p.240). Moscow: Yusticin-form.

8. Leont'ev, A. N. (1975). Deyatel'nost'. Soznanie. Lich-nost'. (p.304). Moscow: Politizdat.

9. Majlis, N. P. (2006). Moya professiya sudebnyj ekspert. (p.168). Moscow: SHCHit-M.

10. Mishchik, S. A. (2014). Mathematical modeling system integrity-curricular activities - the second problem pedagogometriki. Materialy Mezhdunarodnoy nauchnoy konferenctsii "European Innovation" - 30.09.2014. ISJ Theoretical \&Applied Science, 9(17), pp.126128. http://dx.doi.org/10.15863/TAS.2014.09.17.21

11. Obozov, H. H. (1990). Psihologiya mezhlichnostnyh otnoshenij. (p.191). Kiev: Nauka.

12. Reshetova, Z. A. (2013). K voprosu o mekhanizmah usvoeniya i razvitiya. Nacional'nyj psihologiche-skij zhurnal, № 1(9), pp.25-32.

13. Talyzina, N. F. (1984). Upravlenie processom usvoeniya znanij. (p.345). Moscow: MGU. 


\begin{tabular}{|c|c|c|c|c|c|c|}
\hline \multirow{4}{*}{ Impact Factor: } & ISRA (India) & $=3.117$ & SIS (USA) & $=0.912$ & ICV (Poland) & $=6.630$ \\
\hline & ISI (Dubai, UAE & $=0.829$ & РИНЦ (Russia) & $=0.156$ & PIF (India) & $=1.940$ \\
\hline & GIF (Australia) & $=0.564$ & ESJI $(\mathrm{KZ})$ & $=8.716$ & IBI (India) & $=4.260$ \\
\hline & JIF & $=1.500$ & SJIF (Morocco) & $=5.667$ & OAJI (USA) & $=0.350$ \\
\hline
\end{tabular}




\begin{tabular}{|c|c|c|c|c|c|c|}
\hline \multirow{4}{*}{ Impact Factor: } & ISRA (India) & $=3.117$ & SIS (USA) & $=0.912$ & ICV (Poland) & $=6.630$ \\
\hline & ISI (Dubai, UAE & $=0.829$ & РИНЦ (Russia) & $=0.156$ & PIF (India) & $=1.940$ \\
\hline & GIF (Australia) & $=0.564$ & ESJI $(\mathrm{KZ})$ & $=8.716$ & IBI (India) & $=4.260$ \\
\hline & JIF & $=1.500$ & SJIF (Morocco) & $=5.667$ & OAJI (USA) & $=0.350$ \\
\hline
\end{tabular}

